\title{
Ocular Surface Squamous Neoplasia: Clinicopathological Analysis and Treatment Outcome of 65 Cases
}

\author{
Ibrar Hussain and Bakht Samar Khan \\ Department of Ophthalmology, Khyber Teaching Hospital, Peshawar, Pakistan
}

\begin{abstract}
Objectives: To find out the demography, clinical behaviour and outcome of ocular surface squamous neoplasia (OSSN) in North-west Pakistan.

Study Design: Case series.

Place and Duration of Study: Department of Ophthalmology, Khyber Teaching Hospital, Peshawar, Pakistan, from March 2011 to December 2017.

Methodology: All patients with OSSN consulting this department were registered. A special proforma was designed to document demography, clinical features, management, and follow-up of all cases. At the end of study, the data was analysed using SPSS version 25 and the result compiled.

Results: Sixty-five eyes with OSSN were included in the study, in which 40 (61.5\%) were males and 25 (38.5\%) were females. Mean age of the patients was $61.68 \pm 12.76$ years. Twenty-six $(40 \%)$ patients were farmers and exposed to ultraviolet light for prolong period. Fifty-nine $(90.8 \%)$ presented with a painless, reddish mass on ocular surface. Average size of neoplasm at presentation was $18.60 \pm 11.30 \mathrm{~mm}$ in large dimension. Histopathologically, 23 (35.4\%) were carcinoma in situ and $41(63 \%)$ invasive squamous cell carcinoma. During the period of follow-up 41 (63.1\%) cured, 21 (32.2\%) developed recurrence, and 3 (4.6\%) patients passed away.

Conclusion:_OSSN is common in North-west Pakistan. The presentation is late due to certain socio-economic factors; but overall behaviour of the neoplasm is almost the same as mentioned in other studies from different parts of the world.
\end{abstract}

Key Words: Ocular surface squamous neoplasia (OSSN), conjunctival squamous cell carcinoma, Carcinoma in situ.

How to cite this article: Hussain I, Khan BS. Ocular Surface Squamous Neoplasia: Clinicopathological Analysis and Treatment Outcome of 65 Cases. J Coll Physicians Surg Pak 2020; 30(09):970-973.

\section{INTRODUCTION}

Conjunctival squamous cell carcinoma is the most common ocular surface malignancy. ${ }^{1,2}$ It constitutes $4.2 \%$ of all growths of ocular surface. ${ }^{3}$ It includes epithelial dysplasia, carcinoma in situ (CIS) and invasive squamous cell carcinoma (SCC) of conjunctiva. Prolong exposure to solar ultraviolet radiations is considered to be a major risk factor in etiology of this tumor. ${ }^{4,5}$ Conjunctival squamous cell carcinoma usually presents in old age and commonly arise from interpalpebral part of conjunctiva in the form of a nodule, gelatinous mass, leucoplakia or diffuse invasive manner. Long standing and untreated lesion may involve the eyeball and/or orbit.

Surgical excision is the gold standard for treatment of OSSN. ${ }^{6}$

Correspondence to: Dr. Ibrar Hussain, Department of Ophthalmology, Khyber Teaching Hospital, Peshawar,

Pakistan

E-mail:dribrar@hotmail.com

Received: September 05, 2018; Revised: January 20, 2020;

Accepted: January 20, 2020

DOI: https://doi.org/10.29271/jcpsp.2020.09.970
This tumor is treated with complete excision with or without application of mitomycin to the bed and / or cryotherapy. ${ }^{7}$ Some patients need post-excision topical chemotherapy or radiotherapy, while others need enucleation or exenteration, if there is intraocular or intraorbital spread. The purpose of our study wasto evaluate demography, clinicalfeatures, outcome of treatment modalities in our set-up and recurrence of this malignant lesion in North-west Pakistan.

\section{METHODOLOGY}

It was a prospective case series in which 65 eyes of 63 patients, who completed the required follow-up, were included after taking an informed consent. The study was approved by Hospital Ethical Committee. Only biopsy-confirmed cases of conjunctival squamous cell carcinoma were included. Cases with xeroderma pigmentosum were excluded from the study, because that is a separate entity with known cause for skin \& ocular surface tumors. This study was performed at Khyber Teaching Hospital, Peshawar, Pakistan from March 2011 to December 2017, and simple non-probability sampling technique was adopted.

A standard proforma was designed to record the demography, tumor parameters, management procedures and follow-up. 
Minimum follow-up period required for inclusion in the study was six months, although patients earlier included in the study were followed up for longer period (maximum up to 5.5 years).

All eyes were examined on slit lamp; and site, size and morphological pattern of tumor were noted. All small lesions, which could be easily separated from ocular surface, were treated with excisional biopsy, and $0.04 \%$ mitomycin (MMC) application to the surgical bed for three minutes. ${ }^{7}$ Large lesions with feeling of invasion of ocular surface during surgery were combined with partial corneo-sclerectormy. It followed by MMC application for three minutes. Tumors deeply invading the eyeball or orbit, confirmed by CT scan and / or MRI of the orbit, were treated with either enucleation or exenteration, followed by radiotherapy in selected patients.

SPSS version 25 was used for statistical analysis. Categorical variables like gender, patient occupation, morphological and histopathological pattern of lesion, treatment modalities and recurrence were expressed as percentages and continuous variables like age, duration of lesion and size of lesion were expressed as means with standard deviations.

\section{RESULTS}

Sixty-five patients, 40 (61.5\%) males and 25 (38.5\%) females were included in the study. Mean age of all patients was $61.68 \pm$ 12.76 years with range from 27 to 92 years. Occupational analyses show 26 (40\%) farmers, 24 (36.9\%) housewives, 5 (7.7\%) businessmen persons, 2 (3\%) drivers, and 8 (12.3\%) others. Follow-up period ranged from 6 months to 66 months (5.5 years).

Fifty-nine $(90.8 \%)$ patients presented with chronic irritation, redness and mass on ocular surface, $3(4.6 \%)$ patients were referred by general practitioners for pterygium excision and 3 (4.6\%) patients were diagnosed on routine checkup. Average size of lesion in large dimension was $18.60 \pm 11.30 \mathrm{~mm}$ and in small dimension, it was $14.21 \pm 9.43 \mathrm{~mm}$. Morphological pattern of lesions included gelatinous $25(38.5 \%)$, papillomatous $18(27.7 \%)$, leukoplakic $4(6.2 \%)$ and mixed pattern 18 (27.6\%). Histopathologically one (1.5\%) patient had dysplasia, $23(35.4 \%)$ carcinoma in situ and 41 (63\%) invasive SCC. Among invasive, 21 (51.2\%) were well differentiated, 17 (41.5\%) moderately differentiated, 2 (4.9\%) poorly differentiated, and 1 (2.5\%) undifferentiated invasive SCC (Figure 1). Treatment detail is given in Tablel.

Table I: Surgical procedures performed on patients.

\begin{tabular}{|l|c|}
\hline Surgical procedure & $\begin{array}{c}\text { Patients number } \\
\text { and percentage }\end{array}$ \\
\hline Excisional biopsy & $09(13.8 \%)$ \\
\hline Excisional biopsy with mitomycin application & $22(33.7 \%)$ \\
\hline Excision with corneo-sclerectomy with mitomycin & $14(21.6 \%)$ \\
\hline Enucleation & $03(4.6 \%)$ \\
\hline Exenteration & $12(18.5 \%)$ \\
\hline Refused surgery & $05(7.7 \%)$ \\
\hline Total & $65(100 \%)$ \\
\hline
\end{tabular}

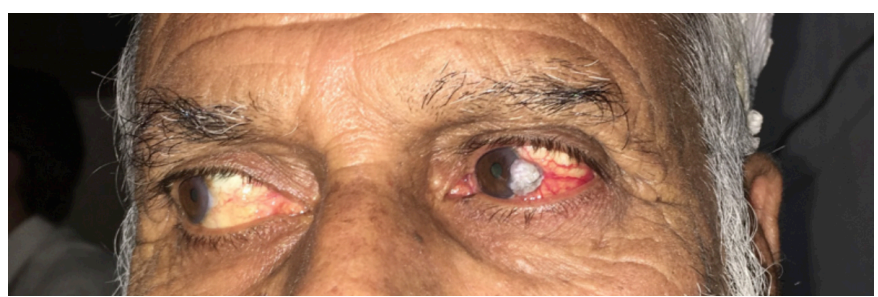

Figure 1: Leukoplakic lesion attemporal limbus.

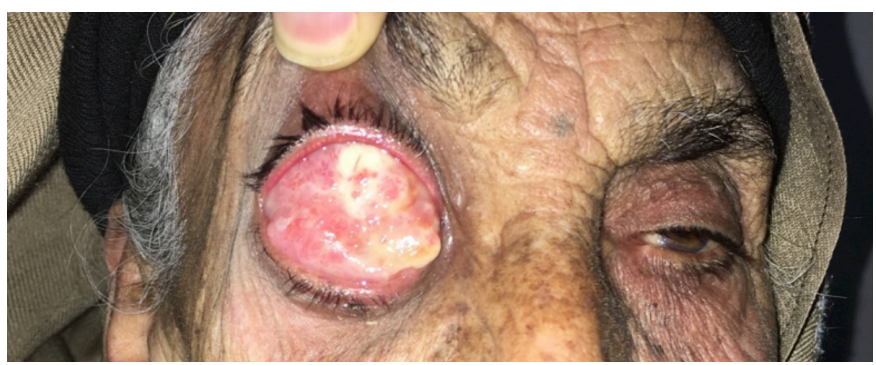

Figure 2: Advance OSSN covering the whole right eyeball.

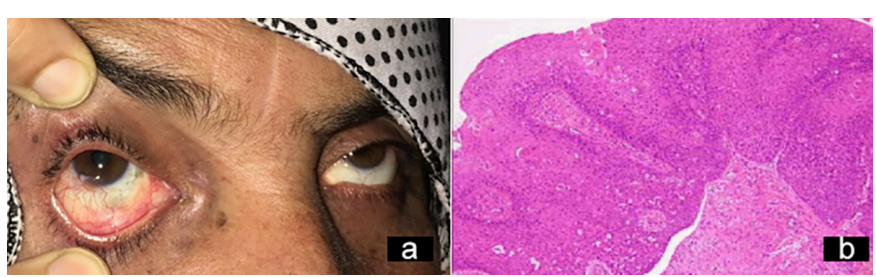

Figure 3: Carcinoma in situ. (a) Clinical presentation. (b) Histopathological picture.

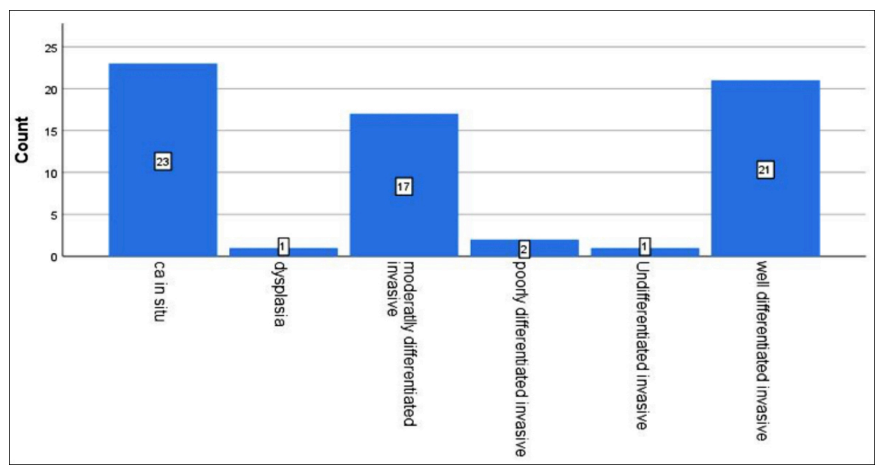

Figure 4: Histopathalogical types of conjunctival OSSN.

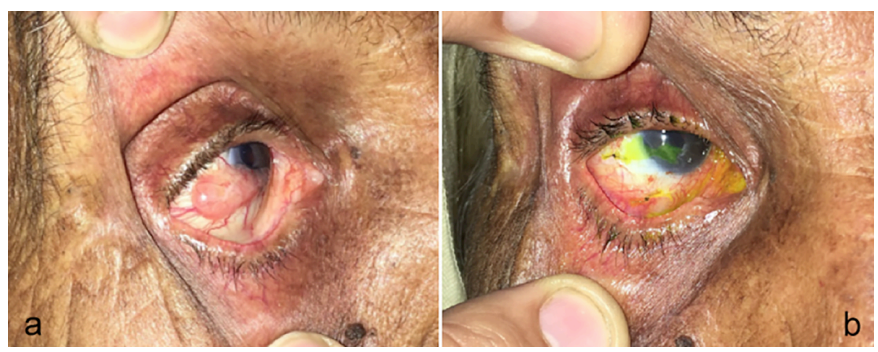

Figure 5: Excision of OSSN: (a) Pre-operative (b) Post-operative.

During the period of follow-up, 41 (63.1\%) patients were cured, 21 (32.2\%) developed recurrence and $3(4.6 \%)$ passed away (cause of death unknown).

\section{DISCUSSION}

Lee and Hirst, first proposed the term ocular surface squamous neoplasia (OSSN) in 1995 to encompass the spectrum of 
dysplasia, carcinoma in situ, and invasive squamous cell carcinoma of ocular surface. ${ }^{1}$

OSSN is a very common tumor in North-west Pakistan which is reflected by the study sample size (65 eyes), which was collected over a period of five years in only one teaching hospital of Peshawar. In a study from another teaching hospital of the same city Peshawar, 36 eyes with OSSN were reported, and this sample size was collected over a span of 3 years. ${ }^{8}$ It is much more common in this part of the world. In one study from Australia, only 26 cases consulted one institution in seven years. ${ }^{9}$ High prevalence of this tumor in this belt may be racial predilection. Pathan race occupying this belt have light skin complexion, which could be one reason for high prevalence. Moreover, $60 \%$ of our patients were farmers by profession, who are exposed to UV light for prolonged period. UV light exposure is one of the proposed etiological factor mentioned in many studies. ${ }^{4,5}$ Tilomerase reverse transcriptase (TERT) has been identified in many cancersassociated withultravoilet lightexposure. In a study, TERT promoter mutations were identified in $43.8 \%$ cases of OSSN. ${ }^{10}$ Average age of patient in this study wass 61.8 years and male to female ratio is approximately $3: 2$, which is consistent with some other studies ${ }^{11}$. In our study mean age of patient with CIS is 57.8 years as compared to that of invasive SCC, which is 62.3 years. This suggests the progressive nature of the neoplasm. This is consistent with an Iranian study, where average age of the patient with CIS is 5 to 9 years less than those with invasive carcinoma. ${ }^{12}$

Clinical presentation of most of patients with OSSN is a painless, reddish growth in interpalpebral area in our study is similar to those presented in other studies. ${ }^{1,9}$

Average duration of symptoms in our study i.e., 9:5 months is quiet long as compared to duration in other studies ${ }^{9}$. This is due to self-neglect by the old people and also due to benign nature of presentation of the disease. Many of these patients are from farflung areas and accessibility to tertiary care centres at Peshawar (Pakistan) is difficult for these patients. This is other reason for delay in presentation. This in turn delays in treatment and increases morbidity.

Average size of lesion in large dimension was $18.60 \pm 11.30 \mathrm{~mm}$ and in small dimension, it was $14.21 \pm 9.43 \mathrm{~mm}$. These figures show that most of our cases fall into T3 \& T4 stages of American Joint Commission on Cancer (AJCC) classification system. ${ }^{13}$ Only $7(10.9 \%)$ cases of current study fall into T2 stage of this classification. Papillomatous and mixed patterns (27.6\% each) and leukoplakia being least common (6.2\%). It presents rarely as pigmented growth, ${ }^{14}$ although in our series none of the growth was pigmented.

As far as histopathology is concerned, about two-third cases $(63 \%)$ of this study were invasive SCC and one-third $(35.4 \%)$ were carcinoma in situ. Among invasive SCC, about half $(51.2 \%)$ were well differentiated, $41.5 \%$ were moderately differentiated and $7.3 \%$ were poorly differentiated or undifferentiated. In a study from Australia on 26 cases of invasive SCC, 3 (11.5\%) were well differentiated, 15 (57.7\%) moderately differentiated, 7 (26.9\%) poorly differentiated to moderately differentiated, and one (3.8\%) poorly differentiated. ${ }^{8}$ In a study from Iran, 274 patients with conjunctival lesions, $40.8 \%$ were invasive SCC, $17 \%$ dysplasia, $16 \%$ carcinoma in situ while rest of the lesions were benign. ${ }^{15}$

Thirty one $(47.5 \%)$ patients underwent simple excision of the lesion along with $4 \mathrm{~mm}$ surrounding normal looking conjunctiva, with or without application of mitomycin ( $0.04 \%$ for 3 minutes) to the bed. Rest of the cases underwent partial corneo-sclerectomy, enucleation and exenteration depending upon the invasion of underlying tissues (Table 1).

Orbital exenteration is needed in quiet a good number of cases, where tumor is extensive and penetrate deep into fornices. In this study, $18.5 \%$ patients underwent exenteration while in another study from a different hospital in the same city of Peshawar, $30.5 \%$ patients underwent exenteration. ${ }^{10}$ In Australian study, $23 \%$ patients underwent exenteration. ${ }^{12}$ In a study from South Pakistan, $18 \%$ of patients underwent enucleation due to intra-ocular invasion. ${ }^{16}$ Many factors, such as coexisting human papillomavirus infection, immunosuppression, delayed access to care and ultraviolet radiation exposure may also influence response to therapy. ${ }^{17}$ Researchers have used topical 1\% 5-Fluoruracil as soletreatment with complete regression achieved in $83 \%$ cases. $^{18,19}$

The reported recurrence rate of OSSN is $15-52 \%$ with an average recurrence of $30 \% .{ }^{11}$ In this study, recurrence occurred in $32.2 \%$ patients, which is consistent with international studies. Recurrence depends upon stage of diseaseat presentation, involvement of underlying tissue and margin clarity after excision. Scleral involvement is a risk factor for recurrence. ${ }^{9}$ In a study on recurrence of OSSN treated with excisional biopsy and cryotherapy, the overall recurrence rate was $7.1 \%{ }^{20}$. In a study on 101 cases of OSSN, 13 (13\%) developed recurrence; tumor size larger than 5-mm, tumors with larger than 2-mm extension onto the cornea and tumor invasiveness on histopathology were associated with statistically significantly higher risk for tumor recurrence. ${ }^{11}$

\section{CONCLUSION}

OSSN is common in North-west Pakistan, possibly due to prolonged exposure to sunlight. The presentation is late due to certain socio-economic factors but overall behaviour of the neoplasm is almost the same as mentioned in other studies from different parts of the world. Such studies are needed in other provinces of Pakistan to know the behaviour of this neoplasm.

\section{ETHICALAPPROVAL:}

Before starting, the study "ethical approval" was taken from IERB of Khyber Medical College / Khyber Teaching Hospital Peshawar, Pakistan.

\section{PATIENTS' CONSENT:}

Informed consent was taken from all patients to include their data in research. 


\section{CONFLICT OF INTEREST:}

The authors declared no conflict of interest.

\section{AUTHORS' CONTRIBUTION:}

$\mathrm{IH}$ : Planning the study, collection \& analysis of data, writing the manuscriptand collection of references.

BSK: Preparation of proforma and data collection, analysis of data and reviewing the manuscript.

\section{REFERENCES}

1. Lee GA, Hirst LW. Ocular surface squamous neoplasia. Svrv Ophthalmol 1995; 39(6):429-50.

2. Grossniklaus Lee HE, Green WR, Luckenbach M. Conjunctival lesion in adults. Cornea 1987; 6(2):87-116.

3. Awan AH, Hashim R, Mushtaq S. Conjunctival Growths. Pak J Ophthalmol 1999;15:165-8.

4. Newton R, Ferlay J, Reeves G, Beral V, Parkin DM. Incidence of squamous cell carcinoma of the eye increases with increasing levels of ambient solar ultraviolet radiation. Lancet 1996; 2:1450-1.

5. Lee GA, Williams G, Hirst LW, Green AC. Risk factors in the development of ocular surface epithelial dysplasia. Ophthalmology 1994; 101(2):360-4.

6. Cicinelli MV, Marchese A, Bandello F. Clinical management of ocular surface squamous neoplasia: A review of the current evidence. Ophthalmol Ther 2018; 7(2):247-62.

7. Sarici AM, Arvas S, Pazarli H. Combined excision, cryotherapy and intraoperative mitomycin C (EXCRIM) for localised intraepithelial and squamous cell carcinoma of the conjunctiva. Graefes Arch Clin Exp Ophthalmol 2013; 251(9):2201-4.

8. Babar TF, Khan MN, Hussain M, Shah SA, Khan MU, Khan MD. Spectrum of ocular surface squamous neoplasia. JColl Physicians Surg Pak 2007; 17(6):344-6.

9. McKelvie PA, Daniell M, McNab A, Loughnan M, Santamaria JD. Squamous cell carcinoma of the conjunctiva: A series of
26 cases. British J Ophthalmolo 2002; 86(2):168-73.

10. Scholz SL, Thomasen H, Reis H, Moller I, Darawsha D, Muller B, et al. Frequent TERT promoter mutations in ocular surface squamous neoplasia. Investigative Ophthalmology \& Visual Science 2015; 56(10):5854-61.

11. Gichuhi S, Macharia E, Kabiru J, Zindamoyen AM, Rono H, Ollando $E$, et al. Clinical presentation of ocular surface squamous neoplasia in Kenya. JAMA Ophthalmol 2015; 133(11):1305-13.

12. Aliakbar-Navahi R, Ashraf MJ, Seirfar N, Koohestani S, Abedi E. Conjunctival lesions: A histopathologic review in Fars Province, Iran. J Ophthalmic Vis Res 2015; 10(2):98-101.

13. Edge SB, Compton CC. The American joint committee on cancer: The 7th edition of the AJCC cancer staging manual and the future of tnm. Ann Surg Oncol 2010; 17(6):1471-4.

14. Kuruvilla P, Kuruvilla A. Pigmented ocular surface squamous neoplasia. Kerala J Ophthalmol 2017; 29:51-3.

15. Asadi-Amoli F, Ghanadan A. Survey of 274 patients with conjunctival neoplastic lesions in farabi eye hospital, tehran 2006-2012. J Curr Ophthalmology 2015; 27(1-2):37-40.

16. Baia MSA, Dareshani S. Ali MA, Khan MS. Squamous cell carcinoma of conjunctiva: Analysis of 15 cases. J Ayub Med Coll 2009; 21(1):146-7.

17. Stone DU. Bridging the knowledge gap for ocular surface squamous neoplasia: Africa and beyond. Lancet Glob Health 2016; 4(6):e347-8.

18. Parrozanni R, Frizziero L, Trainiti S, Testi I, Miglionico G, Pilotto E, et al. Topical 1\% 5-Fluoruracil as sole treatment of corneo-conjunctival ocular surface squamous neoplasia: Long Term Study. BrJ Ophthalmol 2017; 101(8):1094-9.

19. Joag MG, Sise A, Murillo JC, Sayed-Ahmed IO, Wong JR, Mercado C, et al. Ophthalmology 2016; 123:1442-8.

20. Li AS, Shih CY, Rosen L, Steiner A, Milman T, Udell IJ. Recurrence of ocular surface squamous neoplasia treated with excisional biopsy and cryotherapy. American J Ophthalmolo 2015; 160(2):213-9. 